\title{
Biosynthesis of an organofluorine molecule
}

\section{A fluorinase enzyme has been discovered that catalyses carbon-fluorine bond formation.}

A lthough fluorine in the form of fluoride minerals is the most abundant halogen in the Earth's crust, only 12 naturally occurring organofluorine compounds have so far been found ${ }^{1}$, and how these are biosynthesized remains a mystery². Here we describe an enzymatic reaction that occurs in the bacterium Streptomyces cattleya and which catalyses the conversion of fluoride ion and $S$-adenosylmethionine (SAM) to $5^{\prime}$-fluoro-5' -deoxyfluoroadenosine ( $5^{\prime}$-FDA). To our knowledge, this is the first fluorinase enzyme to be identified, a discovery that opens up a new biotechnological opportunity for the preparation of organofluorine compounds.

The rarity of natural fluorinated products contrasts with the identification of about 3,500 naturally occurring halogenated compounds ${ }^{3}$. The available fluoride is largely insoluble - for example, sea water contains 1.3 p.p.m. fluoride and 19,000 p.p.m. chloride, which may help to explain why fluorine's biochemistry has hardly evolved.

The toxin fluoroacetate is the most ubiq-

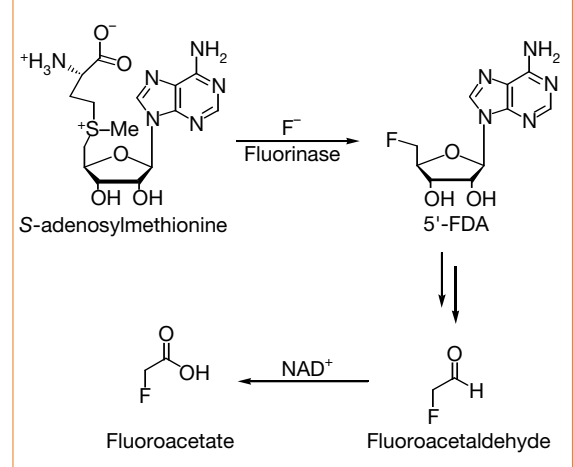

Figure 1 The fluorinase enzyme from Streptomyces cattleya mediates the conversion of $S$-adenosyl-L-methionine (SAM) to $5^{\prime}$-fluoro-5'-deoxyadenosine (5'-FDA). NAD ${ }^{+}$, nicotine adeninedinucleotide. A cell-free protein extract prepared by sonication of washed $S$. cattleya cells at $4{ }^{\circ} \mathrm{C}$ was precipitated with ammonium sulphate (45-60\% saturation) and the precipitate dissolved in $50 \mathrm{mM}$ Tris buffer, $\mathrm{pH} 7.8$, before desalting on a HiTrap column (Pharmacia) and gradient elution from a $15 \mathrm{Q}$ anionexchange column (Pharmacia) with $50 \mathrm{mM}$ Tris, pH 7.8, containing $0-400 \mathrm{mM} \mathrm{KCl}$. Eluted fractions were incubated $(960 \mu l)$ with SAM $(0.4 \mathrm{mM})$ and $\mathrm{KF}(10 \mathrm{mM})$ for $16 \mathrm{~h}$ at $26^{\circ} \mathrm{C}$ and assayed by high-pressure liquid chromatography (HPLC). 5'-FDA was identified by gas chromatography with mass spectroscopy (GC-MS), HPLC and ${ }^{19} \mathrm{~F}-\mathrm{NMR}$ by comparison with a synthetic standard. Synthetic $5^{\prime}$-FDA, prepared by treatment of $2^{\prime}$-0,3'-0-isopropylidene-5'-0-p-tosyladenosine with tetrabutylammonium fluoride ${ }^{9}$ and then with dilute sulphuric acid, yielded fluoroacetate when incubated with $S$. cattleya crude protein extract, identified by ${ }^{19} \mathrm{~F}-\mathrm{NMR}$ comparison to a reference sample. Details of spectroscopic characterization of standards are available from the authors. uitious of the small class of organofluorine compounds and has been identified in more than 40 plant species from all of the continents apart from Antarctica ${ }^{4}$, but its biosynthetic fluorination pathway has not been clearly defined ${ }^{2,5}$. Fluoroacetate is also produced by the bacterium $S$. cattleya ${ }^{6}$ when it is grown in culture medium supplemented with fluoride ions.

We investigated this process of enzymatic fluorination by incubating a partially purified protein extract from $S$. cattleya with fluoride ions and SAM, and monitored the reaction by using high-pressure liquid chromatography (HPLC). The initial product of fluorination in $S$. cattleya was shown to be 5'-FDA by reference to a synthetic standard (Fig. 1 legend); the biotransformed compound and standard 5'-FDA co-eluted on HPLC and (after derivatization) had identical molecular masses and ${ }^{19} \mathrm{~F}$ nuclear magnetic resonsance (NMR) spectra.

Our crude cell-free protein preparation from $S$. cattleya cells was able to mediate the biotransformation of SAM and fluoride ion all the way to fluoroacetate (Fig. 1), indicating that this organism also contains the necessary enzyme activities to convert 5 '-FDA to fluoroacetate. We incubated our synthetic 5'-FDA with the crude protein extract of S. cattleya and directly monitored its bioconversion to fluoro-

\section{Tumour biology}

\section{Herceptin acts as an anti-angiogenic cocktail}

alignant tumours secrete factors that enable them to commandeer their own blood supply (angiogenesis), and blocking the action of these factors can inhibit tumour growth. But because tumours may become resistant to treatments that target individual angiogenic factors by switching over to other angiogenic molecules ${ }^{1,2}$, a cocktail of multiple anti-angiogenic agents should be more effective. Here we show that herceptin ${ }^{3}$, a monoclonal antibody against the cellsurface receptor HER2 (for human epidermal growth factor receptor-2; ref. 4), induces normalization and regression of the vasculature in an experimental human breast tumour that overexpresses HER2 in mice, and that it works by modulating the effects of different pro- and anti-angiogenic factors. As a single agent that acts against multiple targets, herceptin, or drugs like it, acetate by ${ }^{19} \mathrm{~F}-\mathrm{NMR}$ analysis and HPLC. The fluorination reaction seems to involve a nucleophilic attack by fluoride ion at the C-5' carbon of SAM, generating 5'-FDA and concomitantly displacing L-methionine. The mechanism by which $5^{\prime}$-FDA is metabolized to fluoroacetate remains to be established (Fig. 1), although fluoroacetaldehyde $\mathrm{e}^{7,8}$ may be the immediate precursor of fluoroacetate.

David O’Hagan ${ }^{\star}$, Christoph Schaffrath ${ }^{\star}$,

Steven L. Cobb ${ }^{\star}$, John T. G. Hamilton $\dagger$,

Cormac D. Murphy ${ }^{\star}$

${ }^{\star}$ School of Chemistry and Centre for Biomolecular Sciences, University of St Andrews, North Haugh,

St Andrews, Fife KY16 9ST, UK

e-mail:do1@st-andrews.ac.uk

$\dagger$ Microbial Biochemistry Section, Department of

Food Science, The Queen's University of Belfast,

Newforge Lane, Belfast BT9 SPX, UK

1. O'Hagan, D. \& Harper, D. B. Nat. Prod. Rep. 11, 123-133 (1994).

2. O'Hagan, D. \& Harper, D. B. in Asymmetric Fluoro-organic Chemistry (ed. Ramachandran, P. V.) 210-225 (Am. Chem. Soc. Symp. Ser. 746, Washington DC, 1999).

3. Gribble, G. W. Chem. Soc. Rev. 28, 335-346 (1999).

4. Hall, R. J. New Phytol. 71, 855-871 (1972).

5. Peters, R. A. \& Shorthouse, M. A. Nature 216, 80-81 (1967).

6. Sanada, M. et al. J. Antibiot. 39, 259-265 (1986).

7. Moss, S. J. Chem. Commun. 2281-2282 (2000).

8. Murphy, C. D., Moss, J. S. \& O'Hagan, D. Appl. Environ. Microbiol. 67, 4919-4921 (2001).

9. Gani, D. \& Johnson, A. W. J. Chem. Soc. Perkin Trans. 1, 1197-1204 (1982).

Competing financial interests: declared none.

may offer a simple alternative to combination anti-angiogenic treatments.

We found that herceptin treatment significantly reduces the diameter and volume, but not the length, of tumour blood vessels compared with those in tumours treated with a control antibody (Fig. 1a, b); vascular permeability is also significantly reduced $(8.8 \pm 5.7$ and $1.6 \pm 1.1 \times 10^{-7} \mathrm{~cm} \mathrm{~s}^{-1}$ at day 15 in the control and herceptin groups, respectively). Blood vessels in the herceptin-treated tumours thus more closely resemble a normal phenotype. Furthermore, tumour growth is slowed (Fig. 1b) and animal survival is significantly extended (Table 1 ) in response to herceptin treatment. These vascular effects are not dependent on tumour size, as shown by their persistence until the end of the experiment when tumours were largest (6 $\mathrm{mm}$ in diameter; Table 1 ).

To investigate how herceptin achieves this anti-angiogenic effect, we investigated the expression of 23 angiogenesis-related genes by using a gene array. Expression of the pro-angiogenic factors VEGF 